\title{
Effects of fishing on population structure and life history of roman Chrysoblephus laticeps (Sparidae)
}

\author{
Albrecht Götz ${ }^{1,2, *}$, Sven E. Kerwath ${ }^{1}$, Colin G. Attwood ${ }^{3}$, Warwick H. H. Sauer ${ }^{1}$ \\ ${ }^{1}$ Department of Ichthyology and Fisheries Science, Rhodes University, 6140 Grahamstown, South Africa \\ ${ }^{2}$ Elwandle Node, South African Environmental Observation Network (SAEON), 6140 Grahamstown, South Africa \\ ${ }^{3}$ Marine Research Institute, Zoology Department, University of Cape Town, Private Bag X3, 7701 Rondebosch, South Africa
}

\begin{abstract}
The effects of fishing on the population structure and life history of roman Chrysoblephus laticeps, a protogynous hermaphroditic seabream from South Africa, were investigated by comparing fish from protected and exploited areas. Experimental (controlled) fishing and underwater visual census were used to sample roman and to measure population parameters inside and outside the Goukamma Marine Protected Area. Sites chosen for comparisons were adjacent and physically similar to reduce environmental influences on the comparison. Both methods revealed that roman had a higher density and mean size inside the protected area than outside. Age-at-maturity and ageat-sex-change were lower in the exploited area. The shift in age-at-sex-change maintained a constant sex ratio between the exploited and unexploited areas. The condition factor of roman from the protected area was lower than that of roman from the exploited area.
\end{abstract}

KEY WORDS: Fishing effects $\cdot$ Life history $\cdot$ Population structure $\cdot$ Chrysoblephus laticeps $\cdot$ Sparidae $\cdot$ Marine protected area $\cdot$ Sex change

Resale or republication not permitted without written consent of the publisher

\section{INTRODUCTION}

The reduction of fish density and truncation of age structure by fishing may lead to density-dependent changes in life-history patterns and production-related traits (Peterman et al. 1985, Muth \& Wolfert 1986, Policansky 1993, Trippel 1995, Sánchez-Lizaso et al. 2000, Grift et al. 2003, Olsen et al. 2004, Rijnsdorp et al. 2005). Such changes can be phenotypic responses to shifts in the demographic environment (Lenfant 2003), or they may also involve a genetic component, whereby selection pressure is consistent over several generations (Sinclair et al. 2002, Grift et al. 2003, Barot et al. 2004, Pérez-Ruzafa et al. 2006). It is difficult to separate phenotypic and genetic responses (Rijnsdorp 1993).

Density-dependent shifts in life-history and production traits are critical to fishery management as they may be an agent in population regulation, and yet they are very difficult to detect (Rose et al. 2001). As a result, age-structured fishery models usually treat pro- duction-related parameters as invariant across a wide range of population sizes and fishing mortality rates. Most production models build density dependence into the stock-recruit function (Hilborn \& Walters 1992, Myers et al. 1999), but leave adult parameters invariant.

To detect fishery-induced changes, researchers usually look for changes over time and relate these changes to fishing pressure (e.g. Hutchings 2005, Olsen et al. 2005). One drawback of this approach is that environmental changes over time could at least partly explain observed changes in fish life history, and a time series may not encompass extreme densities at which density-dependent effects will be most obvious (Rose et al. 2001). Another approach is to compare fish between areas, a method which is more easily achieved in freshwater systems where populations are frequently isolated (e.g. Magnan et al. 2005). Marine fish populations are less fragmented (Ward et al. 1994), making spatial comparisons difficult, in addition to any uncertainty due to the role of environmental and 
demographic differences between areas (Robertson et al. 2005). As Hilborn \& Ludwig (1993) point out, this makes the research in this area of science more difficult, and progress is largely determined by how many replicates can be performed, the difficulty or impossibility of obtaining controls, and whether environmental treatments can be randomized. Despite these difficulties, we have chosen this approach to study the effects of fishing on reef fish in South Africa for 2 reasons.

Temperate reef fish are the most heavily exploited of marine fishes in South Africa, a predicament that is exacerbated by their slow growth, longevity and hermaphroditic life-styles (Buxton 1993). With the collapse of many species (Griffiths 2000, Griffiths \& Lamberth 2002) the line fishery has been declared to be in a state of emergency. The absence of suitably archived data or long-term data series on catch-at-age and ageat-maturity prevents us from analyzing temporal changes in reef fish life-history and production traits. The only realistic option, therefore, is contemporary comparison between areas that have been subjected to different rates of fishing.

Sex-change in some coral reef fish is known to be density dependent (Collins et al. 1998), yet this characteristic is one of the least well-known agents of density-dependent population regulation (Rose et al. 2001). Sánchez-Lizaso et al. (2000) review studies examining density-dependent changes in life-history traits of exploited populations. They suggest that Marine Protected Areas (MPAs) should be a useful tool for testing the common hypotheses; however, definitive results from comparative studies have been unclear. Two such studies on reef fish that reported some effects that were opposite to what one might expect are of importance here:

(1) Lloret \& Planes (2003) determined the condition of white seabream Diplodus sargus, a sparid reef fish in the Mediterranean, in relation to habitat quality and protection from fishing in a MPA. The post-spawning white seabream in the protected area were in better condition than those in unprotected areas, but the effect of protection on fish condition was uncertain due to better habitat quality within the MPA. A further complicating factor was that the protection was not absolute, and the effect of protection on fish density was unknown.

(2) Buxton (1993) examined the effects of exploitation on life-history traits of 2 seabream species in South Africa by comparing exploited and unexploited populations. Samples of roman Chrysoblephus laticeps and dageraad C. cristiceps were obtained from the large no-take MPA of the Tsitsikamma National Park $\left(360 \mathrm{~km}^{2}\right)$ and the heavily exploited area of Algoa Bay, approximately $150 \mathrm{~km}$ to the east. Both species are hermaphrodites. The mean size of inter-sex fish was not significantly different between the areas for roman, but dageraad changed sex at a smaller size in the exploited area. For both species, sex ratios were skewed towards females in the exploited area, due to the selective removal of larger males. There was no difference in the growth rate of roman between the Tsitsikamma and Algoa Bay populations, but dageraad grew more slowly in the exploited area. This latter result was surprising, but dismissed by the possibility that the populations were intrinsically different.

The studies by Buxton (1993) and Lloret \& Planes (2003) were compromised by differences or potential differences in habitat, and genetic composition between populations that were compared. In this study, we use the MPA approach to re-examine population, life-history and physiological effects of fishing on roman, which is endemic to South Africa's warm temperate coast. Roman is a target species of the hookand-line reef fishery in the area, and stocks of this species are particularly vulnerable to recruitment failure due to a reduction in the number of large, male individuals (Buxton 1993).

The approach we chose was similar to that used by Buxton (1993) and Lloret \& Planes (2003) in that we compared fish between protected and exploited sites, but greater emphasis was placed on selecting sites that were not measurably different in terms of habitat, by comparing fish from the same source of recruitment, and by using comparable methods between areas.

South Africa has a number of MPAs, varying greatly in size. We chose the Goukamma MPA, because it was possible to compare the same population of roman in immediately adjacent areas subject to different treatments (exploited and unexploited), and because this area is central in the range of roman (Branch et al. 1999). Due to the highly resident nature of this species, roman remain in the immediate area of the treatment, where responses can be reliably sampled. Home ranges of post-recruit roman are $<100 \mathrm{~m}$ (Kerwath et al. 2007a).

We tested the hypothesis that fishing reduces density and truncates age structure. Although this effect has been found for a wide range of species and environments (Guénette et al. 1998), it is a prerequisite for testing the second hypothesis that production-related traits vary in response to changes in density and age structure among fish from the same genetic pool. We tested for changes in growth rate, condition, age-atmaturity and age-at-sex-change.

\section{MATERIALS AND METHODS}

Study area. The Goukamma MPA is situated immediately west of Buffalo Bay, on the south coast of the 


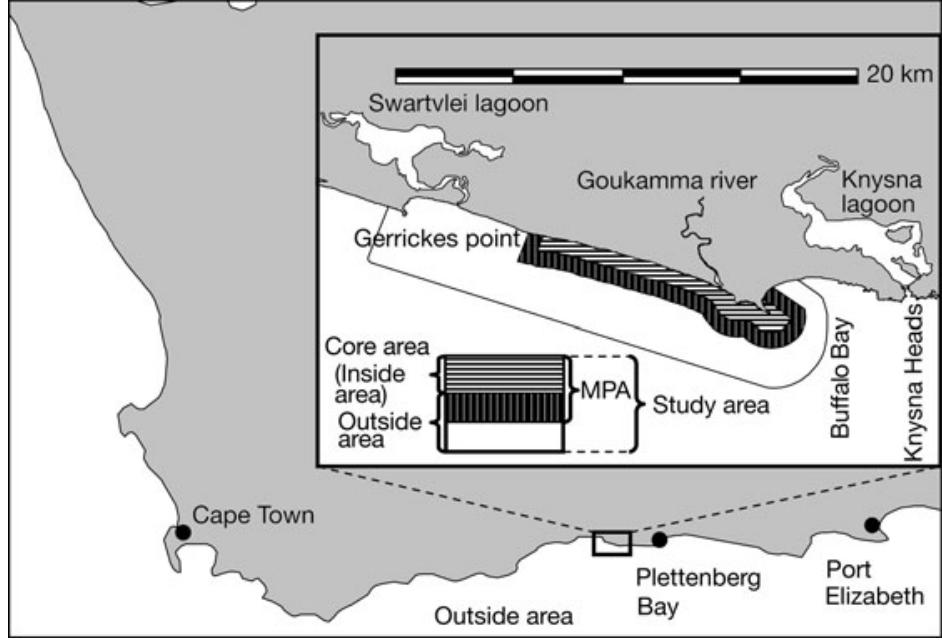

Fig. 1. Map of the study area showing the Goukamma Marine Protected Area (MPA), and the core (inside) and outside areas

rock-sand/sand-rock) was treated as a fixed effect, equal stratification of sample sites across levels was not possible, as no means of a priori determination of bottom type were available.

Depth, temperature, turbidity, reef profile and visibility were treated as random effects. The factor 'season' refers to day-length and was included to identify spawning-related influences. Temperature and season were by no means auto-correlated, as very low temperatures were frequently measured during summer, due to cold upwelling events (Götz 2005).

Although very precise when counting and measuring the length of fish, controlled fishing is a relative method of estimating abundance and a selective method of sampling fish sizes. Underwater visual census (UVC), on the other hand, is less biased as it provides an absolute measure of fish numbers

Cape (Fig. 1). It extends $14 \mathrm{~km}$ along the shoreline and 1 mile offshore. Fishing from boats has been prohibited inside the Goukamma MPA since 1990. The study area includes the MPA and surrounding areas to the south and east, extending $27 \mathrm{~km}$ along the coast and $5 \mathrm{~km}$ offshore.

Sampling was conducted inside and outside the MPA. A topographic survey and year-round oceanographic monitoring programme revealed that both sampling areas were similar with respect to water temperature, turbidity and current velocity (Götz 2005). The reef complex was continuous across the MPA boundary and offered large tracts of reef on either side of the boundary of equivalent depth and reef profile for comparative sampling of fish communities.

Fishing boats were regularly counted during the study. Due to the habit of fishermen to fish as close as possible to the border of the MPA and some deliberate poaching, fishing boats were often encountered inside the MPA. These transgressions were mostly limited to the outer edge of the MPA. Sample sites intended to represent the protected part of the study area were therefore limited to a core area within the MPA (hereafter referred to as 'inside area'), the area in which fishing boats were least often recorded (Fig. 1). Based on 76 boat counts representing 154 boats, an average boat count ratio of 1:11 was found (chi-square tests; $\mathrm{p}<$ $0.001)$ between the inside area of the MPA (0.2 boats $\mathrm{km}^{-2}$ ) and the outside area (2.2 boats $\left.\mathrm{km}^{-2}\right)$.

Experimental design. Sampling sites were stratified across areas (2 levels: inside/outside), season (4 levels: spring/summer/autumn/winter) and time of day (2 levels: morning/afternoon) (fixed effects) for statistical analysis. Although bottom type (3 levels: rock/ and provides measurements over a wide range of fish sizes, but lacks precision. Both methods were used to estimate fish density and size as they are complementary.

Samples of roman Chrysoblephus laticeps across a range of size classes were retained for biological examination to test for differences in life-history parameters that may be related to fishing. To prevent reducing the unexploited roman stock inside the MPA for the duration of the study, samples were taken at the end of the study period in January 2004, which was the middle of the spawning season. Data were collected over a period of $41 \mathrm{mo}$, beginning in September 2000.

Density and size structure of fish. Standardized fishing was conducted at pre-selected fishing stations from a small boat. Sampling stations were stratified across areas, season and time of day. Time, position and environmental data were recorded at each station, once it was ensured that the boat had settled at anchor and would not drift. The position of each station was calculated as the average of the GPS (global positioning system) coordinates recorded during the fishing station.

The fishing team was kept as consistent as possible with no more than 10 trained participants in the entire study. Anglers fished with standard hook sizes and baits. Fishing stations lasted for a minimum of $30 \mathrm{~min}$. All captured fish were measured and returned. A more detailed description of fishing procedures can be found in Götz et al. (2007).

UVC was conducted by SCUBA at pre-selected sites. Sampling sites were stratified across areas, season, time of day and depths between 10 and $30 \mathrm{~m}$. The GPS position of each site was taken directly at the diving 
buoy. Data collection was limited to dives with at least

$3 \mathrm{~m}$ of horizontal visibility.

Four point counts (instantaneous area counts; Thresher \& Gunn 1986) were conducted per dive within $15 \mathrm{~m}$ of the buoy line. Cryptic species were not counted. After each point count sizes of roman were estimated in $5 \mathrm{~cm}$ classes. The accuracy of this method was verified with fish of known size individually tagged with visible implant fluorescent elastomer tags. In 52 trials the actual size was always within the estimated range.

Biological sampling. Roman were collected for morphometric analysis, gonad staging and ageing during the middle of the spawning season (January). The target sample size for each area (inside and outside) was 10 fish for every $20 \mathrm{~mm}$ size class from 140 to $420 \mathrm{~mm}$. Fish in the ranges from 140 to $200 \mathrm{~mm}$ and from 360 to $420 \mathrm{~mm}$ were generally under-represented in the catch and were obtained by spear-fishing using SCUBA. Each fish was measured and weighed. Sagittal otoliths were removed, cleaned and stored dry for later age determination. The gonads were removed and visually staged (Buxton 1987). Sagittal otoliths were embedded in clear casting resin, sectioned to $0.2-0.5 \mathrm{~mm}$ and mounted on slides. Alternating opaque and hyaline zones were used for age determination according to the method described by Buxton (1993).

Environmental data. The depth at fishing stations and dive sites was determined by echo-sounder and pressure gauge, respectively. The point-count depths were averaged to present a dive site depth. Reef profile (or relief) within the $15 \mathrm{~m}$ radius around the buoy line was recorded as the difference between the shallowest and deepest point count depth in metres. At all fishing stations and dive sites, temperature and turbidity measurements were taken with a bathy-turbiditythermograph, and the values were averaged over the bottom $4 \mathrm{~m}$. In addition, the horizontal water visibility was measured with a Secchi disc $1 \mathrm{~m}$ above the bottom at dive sites. Visibility was the preferred measure of water clarity as the authors believe that it is biologically more relevant. As no diving was done prior to or after fishing at that station, turbidity measurements were used for the analyses.

The boat-based echo-sounder was used to identify rocky substrate before a dive. However, the echosounder's display did not allow for a finer classification of substrates, which was done during a dive. For ease of analysis, it was decided to use 4 broad categories: 'rock' or 'sand' if 1 substratum type was clearly dominant, 'rock-sand' if the bottom was comprised of rocky substratum interspersed by a few sandy patches, or 'sand-rock' if mainly sandy substratum with some exposed rocks was present. In cases where only sandy substrate was encountered at a dive site, no biological data were recorded, but depth and bottom type were noted for benthic mapping.

Generalized linear models (GLMs). GLMs were applied to examine the effects of various parameters on the density and size of roman. To find the optimal combination of parameters, the fit of the different models was assessed using the Akaike information criterion (AIC; Akaike 1973). The 'Wald' statistic $(W)$ and its p-level were used to test the significance of each regression coefficient (Harrell 2001).

Before modelling the main effects, second degree interactions between main effects (factors) were modelled. Due to the large number of interaction terms, the models were compromised by statistical over-fitting. Therefore, only combinations involving area were modelled to reduce the number of model parameters. Although it may seem possible for there to be an interaction between season (and/or temperature) and depth, such an interaction would imply that fish move seasonally or in response to shifting water masses. Tagging and telemetry studies have indicated a high degree of 'site fidelity' in roman (Kerwath et al. $2007 a, b)$, which led us to discard these interactions.

Fishing data. The number of roman caught per fishing station was used as an independent sample unit. The response codes in the fishing survey were count or continuous variables (number of roman caught or measured forklength). The distributions of these variables were assumed to be Poisson or normal, respectively.

The log-link function was used for the variables with a Poisson distribution (McCullagh \& Nelder 1995). To model the density of roman in the study area, the following parameters (factors) were included in a GLM (between effects involving area not shown here):

$$
\log (\text { Catch })=\beta_{0}+\beta_{1}(\text { Depth })+\beta_{2}(\text { Temperature })+\beta_{3}
$$$$
(\text { Turbidity })+\beta_{4}(\text { Season })+\beta_{5}(\text { Time Of Day })+\beta_{6}(\text { Area })+\varepsilon
$$

where the $\beta_{i}$ values were the estimated coefficients and $\varepsilon$ is the error. Effort was not included in the GLM model because equal effort was applied at most fishing stations, thereby eliminating the influence of this parameter. We nonetheless assume a linear relationship between catch and effort, and express catch rate as catch per unit effort (CPUE).

The identity-link function was used for the variables with a normal distribution (McCullagh \& Nelder 1995). The forklength model included the following parameters (between effects involving area not shown here):

$$
\begin{aligned}
& \text { Forklength }=\beta_{0}+\beta_{1}(\text { Depth })+\beta_{2}(\text { Temperature })+\beta_{3} \\
& (\text { Turbidity })+\beta_{4}(\text { Season })+\beta_{5}(\text { Time Of Day })+\beta_{6}(\text { Area })+\varepsilon
\end{aligned}
$$

where the $\beta_{i}$ values were the estimated coefficients and $\varepsilon$ is the error. 
UVC data. Due to unfavourable diving conditions in winter, surveys were restricted to the summer months. The density of roman was calculated as number per station. Because individual point counts at dive sites were in close proximity, their data had to be pooled to prevent spatial autocorrelation in the analysis. The response codes fish number and forklength were defined as count and continuous variables, respectively. To model roman density, the following parameters (factors) were included in a GLM (between effects involving area not shown here):

$$
\begin{aligned}
& \log (\text { Count })=\beta_{0}+\beta_{1}(\text { Depth })+\beta_{2}(\text { Temperature })+\beta_{3} \\
& (\text { Bottom })+\beta_{4}(\text { Profile })+\beta_{5}(\text { Visibility })+\beta_{6}(\text { TimeOf Day }) \\
& +\beta_{7}(\text { Area })+\varepsilon
\end{aligned}
$$

To model roman size, the following parameters (factors) were included in a GLM (between effects involving area not shown here):

Length-estimate $=\beta_{0}+\beta_{1}($ Depth $)+\beta_{2}($ Temperature $)+$ $\beta_{3}$ (Bottom) $+\beta_{4}$ (Profile) $+\beta_{5}$ (Visibility) $+\beta_{6}$ (TimeOf Day) $+\beta_{7}$ (Area) $+\varepsilon$

Age and growth calculations. The Von Bertalanffy growth equation was used to model length-at-age:

$$
L_{t}=L_{\infty}\left(1-e^{-K\left(t-t_{0}\right)}\right)
$$

where $L_{t}$ is length at time $t_{1} L_{\infty}$ is the theoretical asymptotic length, $K$ is the body growth coefficient that determines the rate at which $L_{\infty}$ is attained, and $t_{0}$ is the age of fish at zero length. Generalized nonlinear, least-squares procedures were used to estimate growth parameters. Parameter variance was calculated using parametric bootstrapping by resampling 500 bootstrap replicates. The first-order, bias-corrected percentile method (Efron \& Tibshirani 1993) provided confidence intervals from the sorted bootstrap data. To determine whether the von Bertalanffy or the Schnute growth equation modelled growth more realistically, the same non-linear, leastsquares procedure was fitted to the age-length samples using the Schnute growth equation. The fit of the 2 models was compared using a likelihood ratio test. The data for inside and outside were fitted separately, and differences in growth parameters were tested using a likelihood ratio test (Draper \& Smith 1966).

Determination of age and length at maturity and sex-change. The age-at-sexual maturity was determined by fitting the 2-parameter logistic ogive, using a least-squares procedure, to the proportion of reproductively active female fish in each age class (Booth \& Buxton 1997). Parameter variance was calculated using parametric bootstrapping by re-sampling 250 bootstrap replicates. The first-order, bias-corrected percentile method (Efron \& Tibshirani 1993) provided confidence intervals from the sorted bootstrap data. Age-at-50\% sex-change was determined analogously, by fitting the logistic ogive to the proportion of male fish. Calculations were conducted for the inside and outside area separately. Length-at-50\% maturity and length-at-50\% sex-change were determined using the same methods, but with data combined into $10 \mathrm{~mm}$ size classes. Differences in age-at-maturity, age-at-sex-change and the rate of change $(\delta)$ estimated from the inside and outside areas were tested using a likelihood ratio test.

Sex ratios. Sex-at-length keys for each area were constructed from the biological sampling data and used to transform length frequencies of catch and UVC records into sex ratios for both areas. Differences in sex ratios between sampling areas were tested using chisquare contingency tables.

Condition factor. The condition factor $(K)$ describes the relationship between weight and length of a fish (Weatherley 1972):

$$
K=W / L^{3}
$$

where $W$ and $L$ are the weight and forklength. Differences between condition factors of the inside and outside areas were determined with Student's $t$-test after testing for normality and homogeneity of variance.

Comparisons were also carried out within each area between mature and immature roman of similar size classes and between areas using only mature roman of similar size classes. This was done to avoid biases in condition factor calculations due to differences in the age of maturation of fish and differences in lengthfrequency distributions between areas. To investigate whether fish with higher condition factors allocate additional metabolic products into fecundity, differences in gonad weights of mature fish of the same size class were tested using Student's $t$-test.

Determination of fishing pressure. The instantaneous fishing mortality rate $F$ was estimated using the approximation:

$$
F=\ln \left(\frac{N-C}{N}\right)
$$

where $N$ is population density per square kilometre and $C$ is the annual catch per square kilometre.

The average density of roman calculated from UVC data in the outside area (after Kerwath et al. 2007b) was used to determine $N$. The annual catch per square kilometre $(C)$ was calculated as follows, using results from an interview survey conducted at Goukamma (after Götz 2005):

$$
\begin{aligned}
& \mathrm{C}=\text { fishing boats } \mathrm{km}^{-2} \times \text { fishermen } \text { boat }^{-1} \times \text { roman } \\
& \text { caught } \mathrm{h}^{-1} \times \mathrm{h} \mathrm{d}^{-1} \times \mathrm{d} \mathrm{yr}^{-1} \times \% \text { targeting }
\end{aligned}
$$




\section{RESULTS}

\section{Sample size}

During UVC, 496 roman Chrysoblephus laticeps were counted and sizes of an additional 539 individuals were estimated. During fishing surveys, 1089 roman were caught. A total of 168 roman in the inside area and 119 in the outside area were retained for biological sampling. It was not possible to obtain the target of 10 fish per size class for the largest size classes.

\section{Roman densities}

Controlled fishing was conducted at 273 stations. The parameter time of day was discarded during a preceding AIC best-subset analysis. Depth, temperature, season, turbidity and area significantly influenced CPUE (Table 1). CPUE was highest in winter and lowest in autumn, and higher inside (4.3 fish anglerhour $^{-1}$ ) than outside (3.4 fish angler-hour ${ }^{-1}$ ) (Fig. 2a). The distribution of residuals was close to normal (Fig. 2b). Shallow water, low turbidity and warm water were also associated with higher catch rates. There was an interaction between season and area, with lower catches inside the MPA during autumn and winter.

Similar results were obtained from the 44 diving surveys, which represented a combined 177 point counts. The parameters profile and time of day were discarded during a preceding AIC best-subset analysis. Depth, temperature, visibility and area significantly influenced density during counts (Table 2). The UVC data showed a similar-sized area effect to the fishing data (Fig. 2c). The distribution of residuals was close to normal (Fig. 2d). No significant interactions of main effects with area were detected.

\section{Roman sizes}

Depth and area had significant effects on the size of roman caught during fishing surveys, with larger fish caught at shallower stations and in the inside area (Table 3). The parameters time of day, temperature and turbidity were discarded during a preceding AIC best-subset analysis. Roman were, on average, $16 \mathrm{~mm}$ larger in the inside area (Figs. 3a \& 4a). Season also had an effect on roman size; larger fish were caught during summer and smaller fish during autumn (Table 3). The distribution of residuals was close to normal (Fig. 3b). Temperature, turbidity and time of day did not have a significant influence on the size of roman caught by controlled fishing. Interactions of main effects with area were not significant.
Temperature, bottom type, depth and area had a significant effect (Table 4) on the size of the roman estimated during UVC. The parameters time of day, visibility and profile were discarded during a preceding AIC best-subset analysis. Larger roman were encountered in warm water, over rock-sand and on deeper reefs. In contrast, profile, visibility and time of day had no significant influence on roman size. Roman size

Table 1. Chrysoblephus laticeps. Results of the generalized linear model (GLM; Eq. 1) of the influence of season, area, depth, temperature and turbidity on the catch during controlled fishing. ns: not significant; ${ }^{*} \mathrm{p}<0.05_{;}{ }^{* *} \mathrm{p}<0.01$

\begin{tabular}{|lcrc|}
\hline Effect & df & $W$ & $p$ \\
\hline Intercept & 1 & 15.21 & $<0.001^{* *}$ \\
Season & 3 & 71.55 & $<0.001^{* *}$ \\
Area & 1 & 15.72 & $<0.001^{* *}$ \\
Depth & 1 & 17.19 & $<0.001^{* *}$ \\
Temperature & 1 & 15.09 & $<0.001^{* *}$ \\
Turbidity & 1 & 26.38 & $<0.001^{* *}$ \\
Area $\times$ Season & 3 & 11.12 & $0.011^{*}$ \\
Area $\times$ Depth & 1 & 3.39 & $0.066, \mathrm{~ns}$ \\
Area $\times$ Temperature & 1 & 3.39 & $0.065, \mathrm{~ns}$ \\
Area $\times$ Turbidity & 1 & 3.81 & $0.061, \mathrm{~ns}$ \\
\hline
\end{tabular}

Table 2. Chrysoblephus laticeps. Results of the GLM (Eq. 3) of the influence of bottom type, area, depth, temperature and visibility on the counts of roman during underwater visual census (UVC). ns: not significant; ${ }^{*} \mathrm{p}<0.05 ;{ }^{* *} \mathrm{p}<0.01$

\begin{tabular}{|lcrc|}
\hline Effect & df & $W$ & $\mathrm{p}$ \\
\hline Intercept & 1 & 23.11 & $<0.001^{* *}$ \\
Bottom type & 1 & 5.15 & $0.023^{*}$ \\
Area & 1 & 13.87 & $<0.001^{* *}$ \\
Depth & 1 & 2.69 & $0.100, \mathrm{~ns}$ \\
Temperature & 1 & 81.94 & $<0.001^{* *}$ \\
Visibility & 1 & 11.11 & $<0.001^{* *}$ \\
Area $\times$ Bottom type & 1 & 2.10 & $0.148, \mathrm{~ns}$ \\
Area $\times$ Depth & 1 & 0.62 & $0.429, \mathrm{~ns}$ \\
Area $\times$ Temperature & 1 & 0.56 & $0.455, \mathrm{~ns}$ \\
Area $\times$ Visibility & 1 & 0.88 & $0.348, \mathrm{~ns}$ \\
\hline
\end{tabular}

Table 3. Chrysoblephus laticeps. Results of the GLM (Eq. 2) of the influence of season, area and depth on the measured forklength of 1089 roman caught during controlled fishing. ns: not significant; ${ }^{*} \mathrm{p}<0.05 ;{ }^{* *} \mathrm{p}<0.01$

\begin{tabular}{|lcrc|}
\hline Effect & df & $W$ & $\mathrm{p}$ \\
\hline Intercept & 1 & 2426.22 & $<0.001^{* *}$ \\
Season & 3 & 8.40 & $0.039^{*}$ \\
Area & 1 & 19.43 & $<0.001^{* *}$ \\
Depth & 1 & 51.18 & $<0.001^{* *}$ \\
Area $\times$ Season & 3 & 0.23 & $0.973, \mathrm{~ns}$ \\
Area $\times$ Depth & 1 & 0.81 & $0.369, \mathrm{~ns}$ \\
\hline
\end{tabular}


estimated during UVC was, on average, $32 \mathrm{~mm}$ larger in the inside area (Figs. 3c \& 4b). The distribution of residuals was close to normal (Fig. 3d). No significant interactions of main effects with area were detected. inside sex-at-length key skewed the sex ratios towards higher female proportions in the outside area. Decreased size-at-maturity and earlier sex-change in the outside area compensates for the relative scarcity of larger (male) individuals (Table 7).

\section{Age and growth}

The otoliths of 250 fish were readable and used for age and growth calculations. Ages ranged between 2 and $19 \mathrm{yr}$. The fit of the von Bertalanffy and Schnute growth models were not significantly different $(\mathrm{p}=$ 0.570; likelihood ratio test), and we therefore persisted with the more commonly used von Bertalanffy equation. Growth curves (Fig. 5) and parameters were not significantly different between areas (Table 5).

\section{Age-at-maturity and age-at-sex- change}

Age- and length-at-50\% maturity and sex-change were significantly lower in the outside area, although the shape of the ogives were not dissimilar. Roman in the outside area matured $1.3 \mathrm{yr}$ earlier and changed sex $2 \mathrm{yr}$ and 4 mo earlier than roman in the inside area (Table 6). Natural $(M)$ and fishing mortality rates $(F)$ estimated from catch curves were 0.19 and $0.25 \mathrm{yr}^{-1}$ derived from controlled fishing (Fig. 6a) and 0.24 and $0.16 \mathrm{yr}^{-1}$ derived from UVC data (Fig. 6b), respectively.

\section{Sex ratio}

The proportion of females in the catch was significantly lower in the inside area than in the outside area (Table 7). The difference in sex-ratios between areas was not significant in the UVC data.

To demonstrate the effect of reduced size-at-maturity and size-atsex-change on sex ratios, the sex-atlength key appropriate for the inside area was used to calculate the sex ratios of fish in the outside area for the fishing and UVC data. The use of the
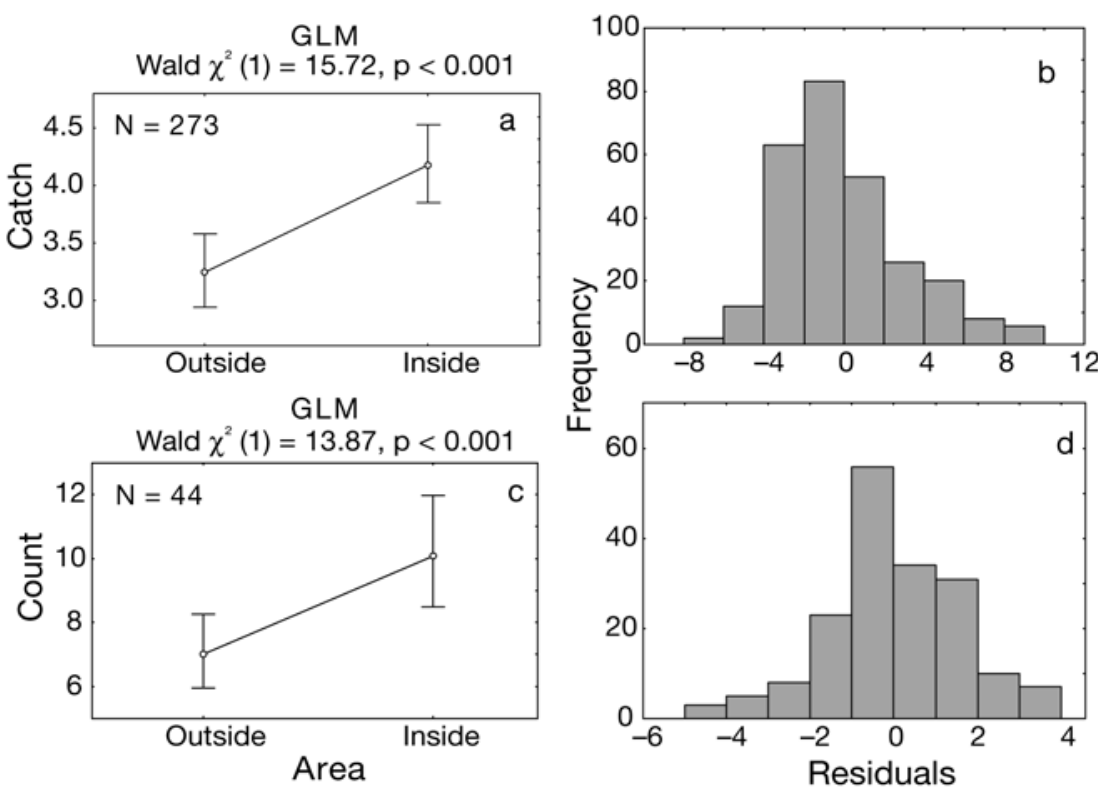

Fig. 2. Chrysoblephus laticeps. (a) Catch at 273 fishing stations and (c) counts during 44 underwater visual census (UVC) surveys of roman in the outside and inside areas. Vertical bars denote $95 \%$ confidence intervals. Respective residuals are shown in (b) and (d). GLM: generalized linear model
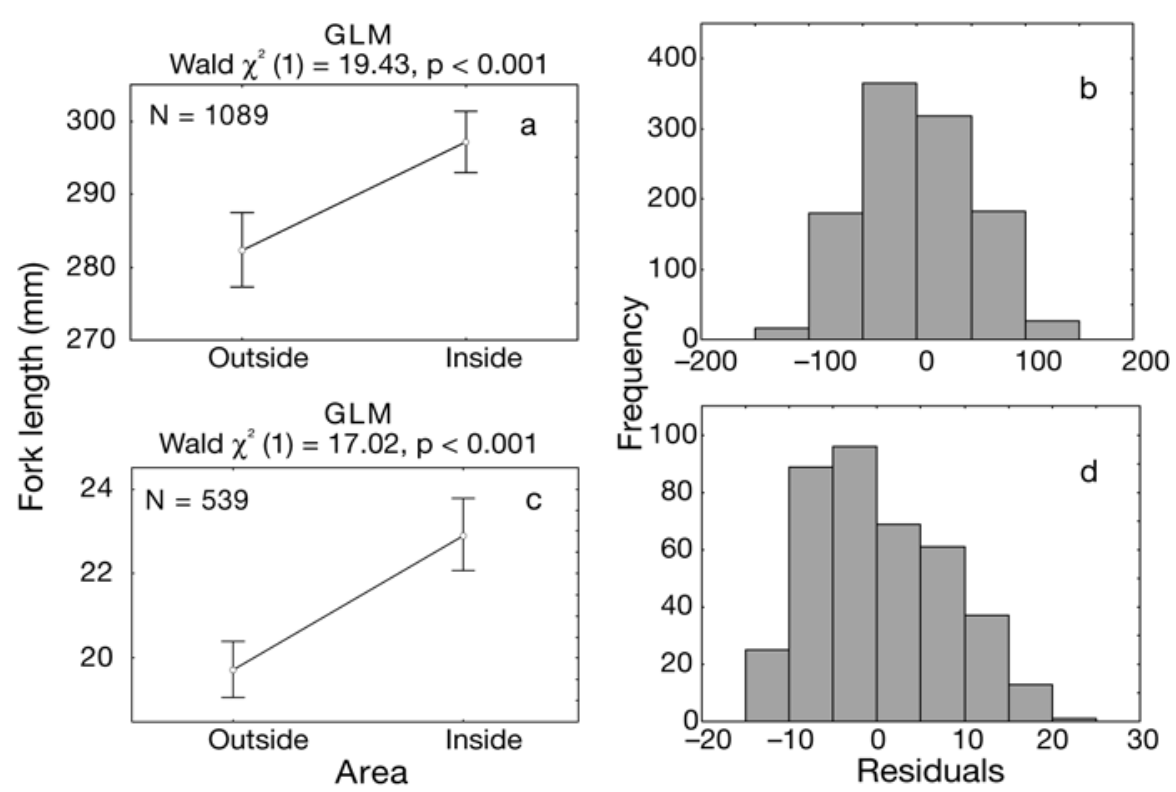

Fig. 3. Chrysoblephus laticeps. (a) Mean sizes of 1089 individuals in the outside and inside areas recorded at 273 stations during fishing surveys and mean size estimates of 539 individuals in the outside and inside areas recorded at 44 dive sites during UVC. Vertical bars denote 95\% confidence intervals. Respective residuals are shown in Panels (b) and (d) 


\section{Condition factor}

There was no difference in condition factor between mature and immature roman within size classes $(\mathrm{p}=$ $0.905)$ and within areas $(p=0.917)$. Differences in mean condition factor between the inside and outside area were tested on mature individuals between 200 and $300 \mathrm{~mm}$. Condition factors were normally distributed $(\mathrm{p}=0.316$ and $\mathrm{p}=0.299$ inside and outside, respectively) and the variances were comparable $(p=0.824)$.

Table 4. Chrysoblephus laticeps. Results of the GLM (Eq. 4) of the influence of bottom type, area, depth and temperature on the size estimates during UVC. ns: not significant; ${ }^{* *} \mathrm{p}<0.01$

\begin{tabular}{lcrc|}
\hline Effect & df & $W$ & \multicolumn{1}{c|}{$\mathrm{p}$} \\
\hline Intercept & 1 & 2.24 & $0.134, \mathrm{~ns}$ \\
Bottom type & 1 & 7.11 & $0.008^{* *}$ \\
Area & 1 & 17.02 & $<0.001^{* *}$ \\
Depth & 1 & 7.67 & $0.006^{* *}$ \\
Temperature & 1 & 11.77 & $<0.001^{* *}$ \\
Area $\times$ Bottom type & 1 & 0.06 & $0.805, \mathrm{~ns}$ \\
Area $\times$ Depth & 1 & 1.00 & $0.317, \mathrm{~ns}$ \\
Area $\times$ Temperature & 1 & 0.56 & $0.453, \mathrm{~ns}$ \\
& & & \\
\hline
\end{tabular}

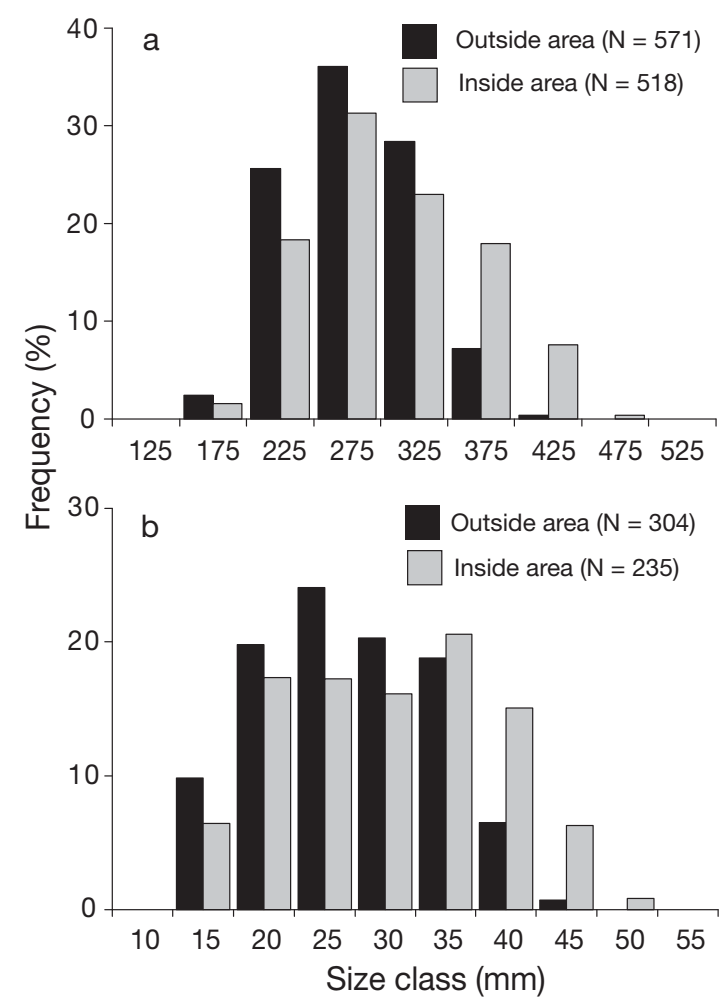

Fig. 4. Chrysoblephus laticeps. Length frequencies of (a) 1089 individuals measured during controlled fishing and (b) 539 individuals estimated during UVC in the inside and outside areas
The mean condition factor of roman from the outside was significantly higher than that of fish from the inside (Fig. 7). Based on the same sub-sample of mature fish, gonad weights did not differ between areas.

\section{Fishing pressure}

The average density of roman $(N)$ calculated from UVC data in the outside area is $19800 \pm 2100$ ind. $\mathrm{km}^{-2}$

Table 5. Chrysoblephus laticeps. Parameter estimates for length-at-age data fitted using the von Bertalanffy model for the inside and outside areas. The p-values derived from likelihood ratio tests for differences between parameters are listed. FL: forklength

\begin{tabular}{|lrrc}
\hline \multirow{2}{*}{ Parameter } & \multicolumn{2}{c}{ Sample area } & $\mathrm{p}$ \\
& Inside & Outside & \\
\hline$L_{\infty}(\mathrm{mm}$ FL $)$ & 504.07 & 510.77 & 0.93 \\
$K\left(\mathrm{yr}^{-1}\right)$ & 0.091 & 0.084 & 0.79 \\
$t_{0}(\mathrm{yr})$ & -1.50 & -2.02 & 0.52 \\
\hline
\end{tabular}

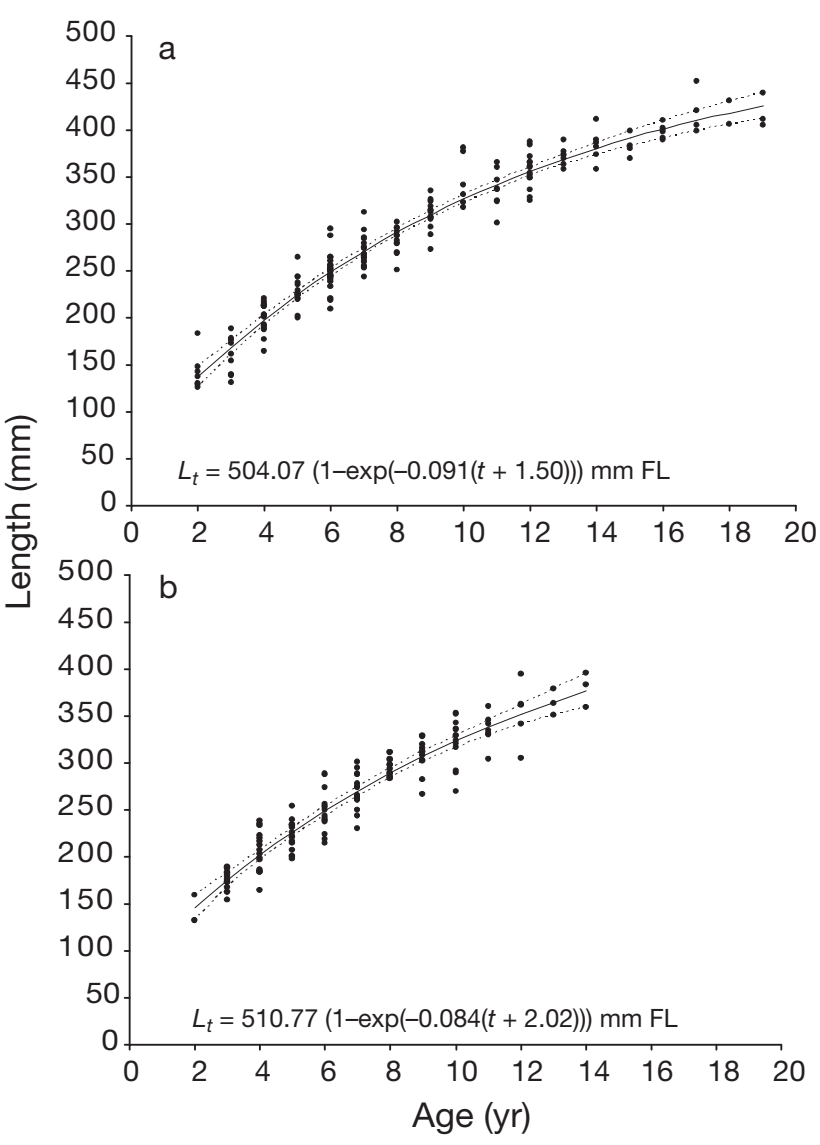

Fig. 5. Chrysoblephus laticeps. Observed individual lengthsat-age $\left(L_{t}\right)$ and the expected von Bertalanffy growth curve, with associated $95 \%$ confidence intervals calculated from 500 bootstraps for the (a) inside area and (b) outside area 
(after Kerwath et al. 2007b). The absolute density of fishing boats in the fished area was 1.03 boats $\mathrm{km}^{-2}$. Each boat carried, on average, 5 (4.8) fishermen and about $8 \%(8.4 \%)$ of fishing boats targeted reef fish (Götz 2005). The average boat trip lasted $7 \mathrm{~h}(7.3 \mathrm{~h}$; unpublished records from the Knysna Ski-Boat Club), and the CPUE of roman in the fished area was 3.4 ind. $\mathrm{h}^{-1}$ (present study). Multiplying these estimates yields an estimated catch of 3762 fish $\mathrm{km}^{-2} \mathrm{yr}^{-1}$. Using Eq. (7), the instantaneous fishing mortality rate $F$ calculates to $0.21 \mathrm{yr}^{-1}$.

Table 6. Chrysoblephus laticeps. A comparison of parameter estimates for age (yr) and length (mm FL) at $50 \%$ maturity and sex-change between the inside and outside areas. The p-values derived from likelihood ratio tests for differences between areas are shown. ${ }^{*} \mathrm{p}<0.05 ;{ }^{* *} \mathrm{p}<0.01$; FL: forklength

\begin{tabular}{|c|c|c|c|}
\hline \multirow[t]{2}{*}{ Parameter } & \multicolumn{2}{|c|}{ Sample area } & \multirow[t]{2}{*}{$\mathrm{p}$} \\
\hline & Inside & Outside & \\
\hline Age-at-50 \% maturity $\left(t_{\mathrm{M} 50}\right)$ & 4.27 & 2.97 & $0.026^{*}$ \\
\hline Logistic delta $\left(\%_{\mathrm{tM} 50}\right)$ & 1.22 & 1.13 & 0.353 \\
\hline Length-at-50\% maturity ( $\left.L_{\mathrm{M} 50}\right)$ & 202.83 & 167.43 & $0.002^{* *}$ \\
\hline Logistic delta (\%oL 50$)$ & 27.50 & 33.61 & 0.636 \\
\hline Age-at- $50 \%$ sex-change $\left(t_{\mathrm{SC} 50}\right)$ & 10.25 & 7.99 & $<0.001^{* *}$ \\
\hline Logistic delta $\left(\%_{\mathrm{tSC}} 50\right)$ & 0.93 & 0.89 & 0.853 \\
\hline Length-at-50 $\%$ sex-change $\left(L_{\mathrm{SC} 50}\right)$ & 330.20 & 289.91 & $<0.001^{* *}$ \\
\hline Logistic delta (\%oLSC50) & 10.78 & 7.68 & 0.310 \\
\hline
\end{tabular}

\section{DISCUSSION}

Investigating the effect of a MPA on fish populations is the flipside of investigating the effects of fishing. Many of the recent studies on MPA effects have chosen this focus, presumably because of the relative novelty of MPAs in fisheries and their anticipated role in the fisheries management crisis (Clark 1996). In natural systems, modern fishing should still be regarded as the perturbation, one which is not fully understood, even for relatively well-studied species such as roman Chrysoblephus laticeps. MPAs should provide an opportunity for studying fishing effects (Sánchez-Lizaso et al. 2000).

In the present study, we have used the MPA not as the subject of the study, but rather as the 'experimental technique'. The investigation probes not only the fishing effects on density and mean size, for which we anticipated a measurable effect from studies on this and similar species, but also some basic physiological effects that may have an impact on fish reproductive capacity and therefore also fishery regulations.
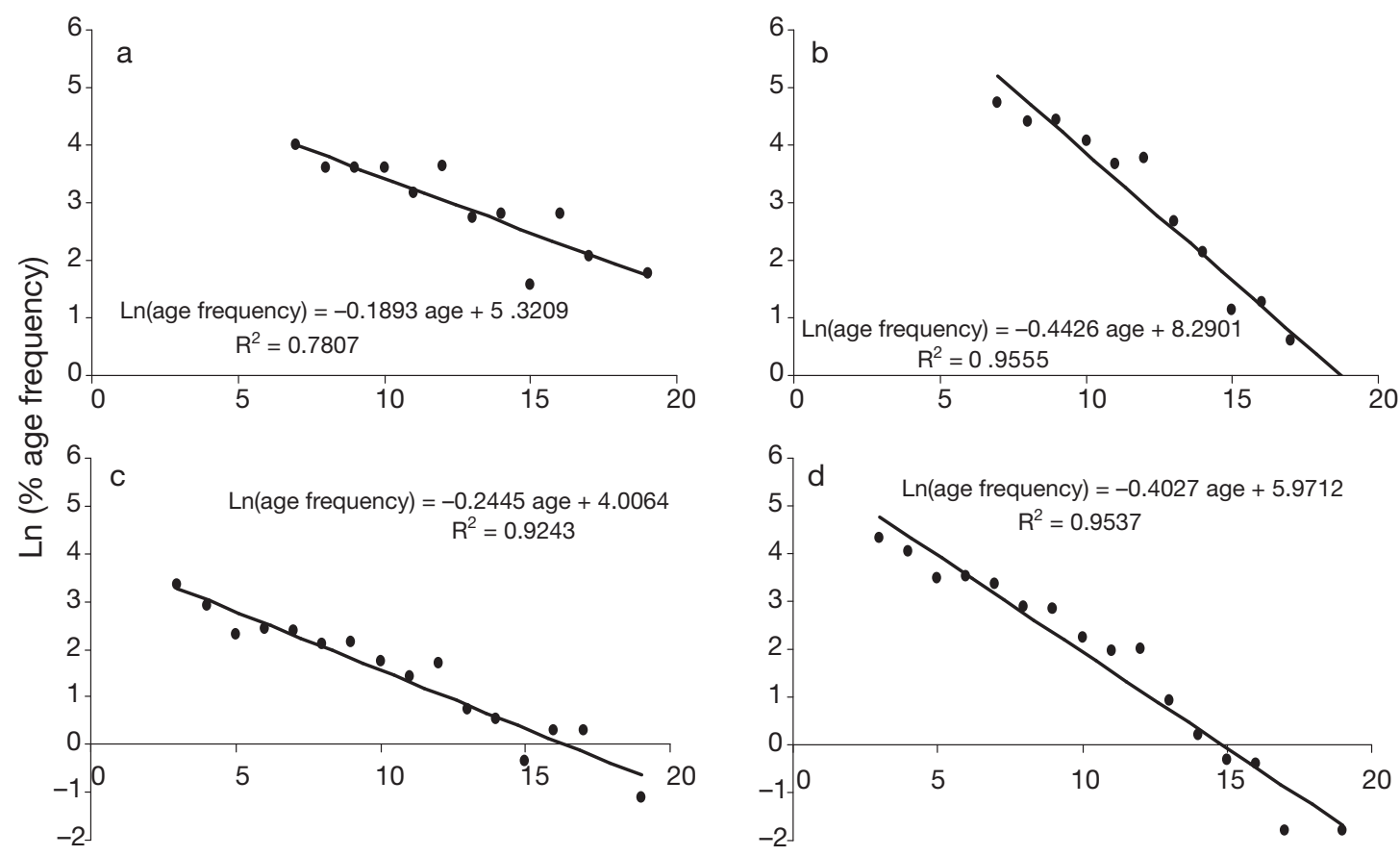

Age (yr)

Fig. 6. Chrysoblephus laticeps. Mortality rates estimated from the descending limbs of catch curves calculated for the inside area (natural mortality rate; $M$ ) and the outside area (total mortality rate; $Z$ ). (a) $M$ and (b) $Z$ using data derived from controlled fishing; (c) $M$ and (d) $Z$ using data derived from UVC 
Table 7. Chrysoblephus laticeps. Comparison of sex ratios (expressed as female:male ratio) between inside and outside areas in the fishing and UVC data sets. Expected sex ratios for the outside area using the sex-at-length keys for the inside area are shown to demonstrate the compensating effect of changes in age-at-maturity and age-at sex-change. The results of chi-squared tests on the differences between areas are listed as p-values

\begin{tabular}{|lcccccc|}
\hline & \multicolumn{3}{c}{ Observed sex ratio } & \multicolumn{3}{c|}{$\begin{array}{c}\text { Sex ratio using inside } \\
\text { sex-at-length key }\end{array}$} \\
& Female & Intersex & Male & Female & Intersex & Male \\
\hline Controlled fishing & & & & & \\
Inside & 1.5 & 0.4 & 1.0 & 1.5 & 0.4 & 1.0 \\
Outside & 1.0 & 0.2 & 1.0 & 4.0 & 1.0 & 1.0 \\
Overall & 1.4 & 0.3 & 1.0 & & & \\
p & $<0.01^{* *}$ & $<0.01^{* *}$ & & & & \\
UVC & & & & & & \\
Inside & 4.9 & 0.5 & 1.0 & 4.9 & 0.5 & 1.0 \\
Outside & 4.1 & 0.3 & 1.0 & 11.3 & 0.8 & 1.0 \\
Overall & 5.2 & 0.4 & 1.0 & & & \\
p & $>0.1$ & $<0.05^{*}$ & & & & \\
\hline
\end{tabular}

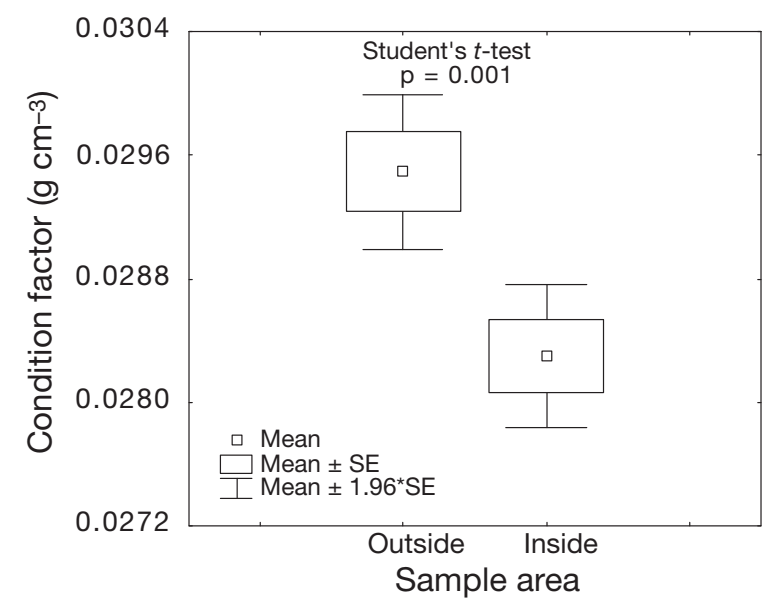

Fig. 7. Chrysoblephus laticeps. Comparison of mean condition factors of mature roman between 200 and $300 \mathrm{~mm}$ sampled in the inside and outside areas

Roberts \& Hawkins (2000) discuss some of the problems inherent in MPA studies, including the selection of suitable controls. Regardless of their 'reverse' perspective, in which they seek suitable exploited sites for controls, their recommendations have application here. Of particular concern is the spatial separation of the sites. Too far, and biogeographic and habitat changes influence the comparison. Too close, and the sites cannot be regarded as independent.

We deliberately chose sites that were immediately adjacent and physically indistinguishable. Indeed, the sites were on the same reef complex. The fish from the 2 areas almost certainly originated from the same recruitment source. Current measurements in the study area were conducted with a surface drogue
(Götz 2005), instead of a conventional, moored current meter, as this approach is superior for describing water tracks within the mixed surface layer, and specifically for the detection of areas of water retention, which may introduce variability in recruitment (Attwood et al. 2002). Roman eggs undergo a pelagic phase lasting $30 \mathrm{~d}$ (Brownell 1979, Tilney et al. 1996). The lack of any areas of water retention suggests that, during this time, dispersal over distances greater than the extent of the study site can be expected (Götz 2005).

The comparison of fish density between exploited and unexploited areas is therefore likely not to be a true representation of the effect of fishing on roman, as the comparison will not detect the effect of 'recruitment overfishing' (Bohnsack \& Ault 1996).

A second factor that causes the results of this study to underestimate the effect of fishing is the amount of poaching in the MPA. The effort gradient of 1:11 between the 2 areas was nonetheless strong enough to result in measurable differences.

Although the distance between study sites in each of the areas was small (on the order of $1 \mathrm{~km}$ ), this distance was far greater than the home range of roman. Only a small minority of roman studied by telemetry (Kerwath et al. 2007a) and tagging (Kerwath et al. 2007b) were found to leave their home range, which measures about 1 ha. Consequently, the effect of the fishing gradient on post-recruit roman should be conserved in each of the immediately adjacent areas, which was comparable in terms of depth, current pattern and turbidity. It is likely therefore that the statistical models of mean size, age-at-sex-change and condition factor presented here reflect 'fishing-induced' changes. Prior to discussing these, however, we need to consider the magnitude of fishing that caused such changes.

Using fishery survey data (Eq. 7), the instantaneous fishing mortality rate $F$ calculates to $0.21 \mathrm{yr}^{-1}$. By comparison, the age structure of roman in catch and UVC data yields $F$ estimates of -0.25 and $0.16 \mathrm{yr}^{-1}$, respectively. Estimates of natural mortality rate $(M)$ from the MPA are 0.19 and $0.24 \mathrm{yr}^{-1}$ for fishing and diving, respectively (Fig. 6). Therefore, for the Goukamma area, $F=Z-M$ is on the same order as $M$, suggesting optimal exploitation (Gulland 1971). Fishing pressure near metropolitan areas, however, is estimated to be greater (Buxton 1992).

The comparison of data across the MPA boundary adds to the many studies showing that local protection 
results in measurably higher density and mean size (Hawkins \& Roberts 2003). Fishing effort was the single most important factor determining roman densities in the study area. Lower roman density under exploitation was also recorded by Buxton \& Smale (1989), Burger (1990), Lechanteur (2004) and Smith (2005) at various locations along the South African southern coast, and, in the present study, roman density is negatively correlated with fishing intensity across all areas (Fig. 8).

A conspicuous effect of fishing is a decrease in mean fish sizes (Leaman 1991). In the present study, the mean size trends compliment the CPUE comparison among different sites. The average size of roman was smaller in the exploited area, as measured by controlled fishing and UVC. Higher mean sizes of roman were measured by Buxton (1987) and Smith (2005) inside the Tsitsikamma National Park (NP), compared to sites off Port Elizabeth and Plettenberg Bay, respectively. A high mean size of roman (313 mm) was found in the central area of the Tsitsikamma NP, which was established $42 \mathrm{yr}$ ago and where no fishing (including illegal fishing) takes place. A mean size of $302 \mathrm{~mm}$ was recorded in the younger and smaller Goukamma MPA $\left(10 \mathrm{yr}, 40 \mathrm{~km}^{2}\right)$, where poaching was reported. Yet outside of the MPA, mean size was further reduced to $279 \mathrm{~mm}$. In a heavily exploited area (Plettenberg Bay), the mean size is $263 \mathrm{~mm}$.

The parameters of the growth curve and lengthweight relationship for roman at Goukamma (both areas combined) are not different from those estimated for the entire southern coast by Buxton (1987), indicating uniformity in the population and environmental condition across the range. Differences in growth rates as a response of populations to exploitation have been demonstrated by Ricker (1981), Godø \& Moksness (1987) and Choat et al. (2003) for salmon Oncor-

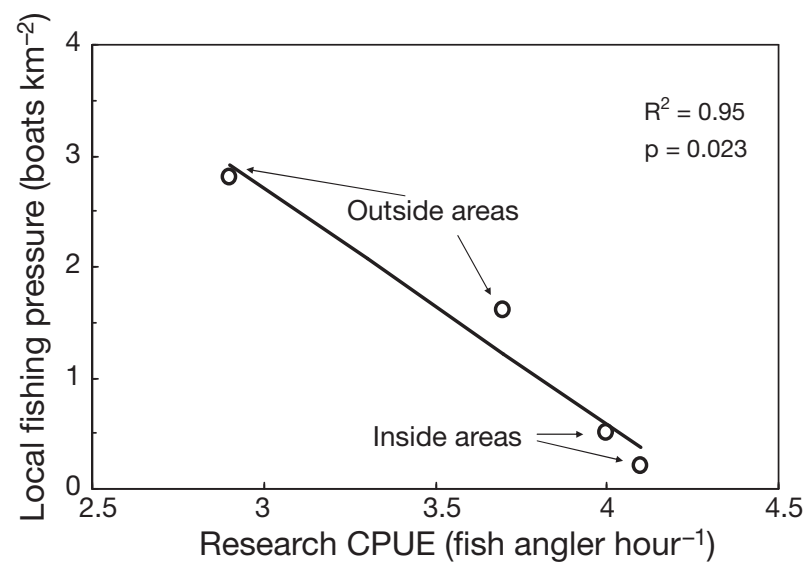

Fig. 8. Chrysoblephus laticeps. Average local fishing pressure and controlled fishing catch per unit effort (CPUE) for roman in 4 areas comprising the study area hynchus spp., cod Gadus morhua and stoplight parrotfish Sparisoma viride, respectively. Faster growth under exploitation could be explained by reduced competition for food (Craig 1985). On the contrary, slower growth could be caused by size-selective fishing gear imposing high mortality in fast-growing individuals (Ricker 1969). In the present study, there was no difference in growth parameters between the protected and the exploited part of the roman population. Similarly, Buxton (1987) found no difference in the growth of roman between the Tsitsikamma NP and the Port Elizabeth area. However, he found reduced growth rates for dageraad at the exploited site. This congeneric species is slower growing and longer lived than roman, and was subjected to a significantly higher fishing mortality than roman (Buxton 1993). As fishing mortality for roman at Goukamma was estimated to be 3- to 4-fold lower than that estimated for dageraad in the Port Elizabeth area (Buxton 1993), it is possible that higher rates of fishing mortality may have reduced the growth rate of roman in other areas along the South African coastline.

Fishing was found to be the most likely cause of a decrease in the age-at-sexual maturity for North Sea plaice Pleuronectes platessa (Rijnsdorp 1993), Northeast Arctic cod Gadus morhua (Jørgensen 1990) and Norwegian herring Clupea harengus (Toresen 1986). Among sequential hermaphrodites, fishing can reduce the proportion of males or females in the population. In compensation, age-at-sex-change may also be reduced (Buxton 1993, Coleman et al. 1996, McGovern et al. 1998, Hawkins \& Roberts 2003, Lenfant 2003). The age-at-sex-change is likely to be controlled by behavioural interactions between males and females (Robertson 1972, Shapiro 1980, Sakai \& Kohda 1997, Sakai et al. 2001). In the present study, fishing mortality was found to reduce the frequency of larger size classes in the sample collected outside the MPA. This reduction in the number of large males most likely reduced age- and size-at-maturation and at sexchange, without reducing the male to female ratio. Our results suggest that phenotypic plasticity can maintain the sex ratio in a population of sequential hermaphroditic fish under moderate fishing pressure.

Contrary to the expected pattern, the sex ratio was found to shift slightly in favour of males outside the reserve when analyzing the fishing data set. The same comparison of sex ratios between the areas using UVC data did not show a significant difference. The UVC method was less selective than fishing and covered a wider size range, which explains the higher female to male ratio than that calculated from the fishing data. Differences in sex ratio between areas are therefore in doubt, but it is possible that the trend, evident in both data sets, of lower female to male ratios in the fishing 
area is real. The only possible explanation for such a trend is a tendency to over-compensate for the loss of males by a shift in age-at-sex-change.

The overall sex ratio (female to male) at Goukamma was higher than that reported for Tsitsikamma, which is a larger and older MPA (Buxton 1987). At heavily exploited sites, Buxton (1987) reported female to male ratios much higher (13:1) than those reported for Goukamma and Tsitsikamma. A possible explanation for the heavily skewed sex ratios found by Buxton's comparison may relate to the difference in fishing pressure in the exploited area. A higher fishing mortality possibly reduced the male component to an extent that could not be fully compensated by a shift in ageat-sex-change. In the study by Buxton (1993), the exploited area was close to Port Elizabeth, a large coastal urban area with a population of 1.1 million and larger numbers of recreational and commercial line fishers than in the Goukamma area (Buxton 1987).

A study on white seabream inside and outside a Mediterranean MPA by Lenfant (2003) showed that females were present in 2 different age distributions, with younger females outside the MPA. However, the genetic differentiation of samples collected inside and outside the MPA was weak, and it was suggested that the 'reserve effect' was phenotypic. Strong currents and mixing, broadcast spawning and general habitat uniformity across the study area means that it is unlikely that a temporal genetic variation due to recruitment variability, alteration of population size, or random or selective post-settlement mortality exists at Goukamma, in contrast to other studies that found high genetic differentiation among close localities (e.g. Lenfant \& Planes 2002, González-Wangüemert et al. 2004, Almany et al. 2007, Carreras-Carbonell et al. 2007, González-Wangüemert et al. 2007). The similarity of the design of our study to that of Lenfant (2003), i.e. distance of $5 \mathrm{~km}$ between sample sites, environment (shallow temperate rocky reefs), subject (sparid reef fish with comparable growth, size and behaviour) and methods (sampling during a short time interval over comparable reefs), suggests that changes in ageat-sex-change are likely to represent phenotypic plasticity.

The higher condition factor for roman outside of the Goukamma MPA was a particularly interesting result and has not been reported in the literature on resident reef fish. This is likely to be due to a reduced competition for food outside of the reserve. During periods of food deprivation, ovarian growth may have priority over somatic growth, as is true for short-lived fish, such as the three-spined stickleback Gasterosteus aculeatus (Wootton 1977) and the medaka Oryzias laticeps (Hirshfield 1980). In long-lived fish, such as the winter flounder Pseudopleuronectes americanus, patterns of allocation of energy during starvation often favour the soma (Tyler \& Dunn 1976). In our study, roman with higher condition factors did not allocate more metabolic products into fecundity. Considering that roman is a rather long-lived species, estimated to live for up to 19 yr in the study area (Götz 2005), this result contradicts findings on the winter flounder. It can be argued, however, that the results on winter flounder are derived from experimental food deprivation, whereas the lower food availability for roman inside an MPA represents the natural (unexploited) situation and is therefore not comparable to artificial starvation. These results suggest that roman do not compensate for population depletion by increasing fecundity, at least not over the range of depletion observed in the fishing area at Goukamma.

\section{Implications}

The approach to the experimental design, such as the use of complementary methods of assessment, standardization of methods and descriptions of physical habitat and benthic community structure have reduced many of the uncertainties that have troubled MPA studies. By accounting for environmental influence, the present study was able to place the relative effects of fishing on a reef fish population into perspective. Although fishing pressure at Goukamma can be considered moderate in relation to other sites (Buxton 1992), changes due to fishing in density, size structure and physiology were measured. Using a small MPA, we showed that even a moderate rate of fishing mortality can decrease density and size of roman, but also that moderate fishing mortality allowed the population of sequential hermaphroditic roman to maintain a healthy sex ratio outside of the MPA. As far as we are aware, this has not been previously documented.

Reductions in size-at-maturity and sex-change will nevertheless reduce fecundity and recruitment, as it is likely that larger fish are more fecund (Brouwer \& Griffiths 2005, Kamler 2005, Van Der Lingen et al. 2006). Given the limited catch and effort data available for South Africa, these results are also important in future stock assessments. As noted by Buxton (1992), the sexchanging nature of roman complicates the use of perrecruit model predictions. Age-at-maturity and age-atsex-change are not invariant, but respond to fishing mortality. Such changes are difficult to model in a continuous manner, especially in per-recruit integrals that treat such parameters as fixed.

Although fisheries compliance in South Africa has received attention with increasing law enforcement activities and capacity (Hauck \& Kroese 2006), there is still little attention given to inshore fisheries by recre- 
ational and commercial operators. In the present study, relative fishing effort inside the MPA was only slightly lower than outside. Only within the core zone, half the size of the designated MPA, was the fishing effort close to zero. Insufficient funds lead to poor enforcement (Pritchard 1993) and sometimes uncontrolled poaching, which can render MPAs ineffective as management tools (Klima et al. 1986, Jennings et al. 1996, Maliao et al. 2004). South Africa's MPAs are troubled by poor resources and poaching (Lemm \& Attwood 2003). Unless the compliance problems are addressed adequately, future MPA initiatives should take into account the possibility of designing a buffer zone where some infringement of the regulations will be inevitable. This suggests that MPAs, in general, should be designed larger than the targeted area for protection, especially where enforcement or management is poor.

In conclusion, the consistency of our results, achieved by using different methods of assessment and analysis, underlines the potential of the experimental design to detect relatively small differences in biological indicators. This high-resolution approach is of particular importance when investigating the effectiveness of small MPAs and could therefore be used as a guideline for similar research efforts.

Acknowledgements. This project was funded in part by the National Research Foundation and the Marine Living Resources Fund. The Elwandle Node of the South African Environmental Observation Network (SAEON) provided additional assistance. The fieldwork would not have been possible without the voluntary assistance of a number of anglers and divers from the Sedgefield and Knysna areas and the support offered by Cape Nature.

\section{LITERATURE CITED}

Akaike $H$ (1973) Information theory and an extension of the maximum likelihood principle. In: Petrov N, Csaki F (eds) Proceedings of the 2nd international symposium on information theory. Akademiai Kiado, Budapest, p 267-281

Almany GR, Berumen ML, Thorrold SR, Planes S, Jones GP (2007) Local replenishment of coral reef fish populations in a marine reserve. Science 316:742-744

Attwood CG, Allen JC, Claassen PJ (2002) Nearshore surface current patterns in the Tsitsikamma National Park, South Africa. S Afr J Mar Sci 24:151-160

Barot S, Heino M, O'Brien L, Dieckmann U (2004) Long-term trend in the maturation reaction norm of two cod stocks. Ecol Appl 14:1257-1271

Bohnsack JA, Ault JS (1996) Management strategies to conserve marine biodiversity. Oceanogr 9:73-82

Booth AJ, Buxton CD (1997) The biology of the panga, Pterogymnus laniarius (Teleostei: Sparidae), on the Agulhas Bank, South Africa. Environ Biol Fishes 49:207-226

Branch GM, Griffiths CL, Branch ML, Beckley LE (1999) Two oceans-a guide to the marine life in southern Africa. David Philip Publishers, Cape Town
Brouwer SL, Griffiths MH (2005) Reproductive biology of carpenter seabream (Argyrozona argyrozona) (Pisces: Sparidae) in a marine protected area. Fish Bull (Wash DC) 103:258-269

Brownell CL (1979) Stages in the early development of 40 marine fish species with pelagic eggs from the Cape of Good Hope. Ichthyol Bull Rhodes Univ 40:1-84

Burger LT (1990) The distribution patterns and community structure of the Tsitsikamma rocky littoral ichthyofauna. MSc dissertation, Rhodes University, Grahamstown

Buxton CD (1987) Life history changes of two reef fish species in exploited and unexploited marine environments. PhD dissertation, Rhodes University, Grahamstown

> Buxton CD (1992) The application of yield-per-recruit models to two South African sparid reef species, with special consideration to sex change. Fish Res 15:1-16

Buxton CD (1993) Life history changes in exploited reef fishes on the east coast of South Africa. Environ Biol Fishes $36: 47-63$

> Buxton CD, Smale MJ (1989) Abundance and distribution patterns of three temperate marine reef fish (Teleostei: Sparidae) in exploited and unexploited areas off the southern Cape coast. J Appl Ecol 26:441-451

Carreras-Carbonell J, Macpherson E, Pascual M (2007) High self-recruitment levels in a Mediterranean littoral fish population revealed by microsatellite markers. Mar Biol 151:719-727

Choat JA, Robertson DR, Ackerman JL, Posada JM (2003) An age-based demographic analysis of the Caribbean stoplight parrotfish Sparisoma viride. Mar Ecol Prog Ser 246:265-277

Clark CW (1996) Marine reserves and the precautionary management of fisheries. Ecol Appl 6:369-370

> Coleman FC, Koenig CC, Collins LA (1996) Reproductive styles of shallow-water groupers (Pisces: Serranidae) in the eastern Gulf of Mexico and the consequences of fishing spawning aggregations. Environ Biol Fishes 47: 129-141

Collins LA, Johnsosn AG, Koenig CC, Baker MS (1998) Reproductive patterns, sex ratio, and fecundity in gag, Mycteroperca microlepis (Serranidae), a protogynous grouper from the northeastern Gulf of Mexico. Fish Bull (Wash D C) 96:415-427

Craig JF (1985) Aging in fish. Can J Zool 63:1-8

Draper NR, Smith H (1966) Applied regression analysis. Wiley, New York

Efron B, Tibshirani RJ (1993) An introduction to the bootstrap. Chapman and Hall, London

Godø OR, Moksness E (1987) Growth and maturation of Norwegian coastal cod and Northeast Arctic cod under different conditions. Fish Res 5:235-242

González Wangüemert M, Pérez-Ruzafa A, Marcos C, GarcíaCharton JA (2004) Genetic differentiation of Diplogus sargus (Pises: Sparidae) populations in SW Mediterranean. Biol J Linn Soc 82:249-261

González-Wangüemert M, Pérez-Ruzafa Á, Cánovas F, GarcíaCharton JA, Marcos C (2007) Temporal genetic variation in populations of Diplodus sargus from the SW Mediterranean. Mar Ecol Prog Ser 334:237-244

Götz A (2005) Assessment of the effect of Goukamma Marine Protected Area on community structure and fishery dynamics. PhD thesis dissertation, Rhodes University, Grahamstown

> Götz A, Kerwath SE, Attwood CG, Sauer WHH (2007) Comparison of the effects of different linefishing methods on catch composition and capture mortality of South African temperate reef fish. Afr J Mar Sci 29:177-185 
Griffiths MH (2000) Long-term trends in catch and effort for the Cape commercial linefishery: snapshots of the 20th century. S Afr J Mar Sci 22:81-110

Griffiths MH, Lamberth SJ (2002) Evaluating the marine recreational fishery in South Africa. In: Pitcher TJ, Hollingworth C (eds) Recreational fisheries: ecological, economic, and social evaluation. Blackwell Science, Oxford, p 227-251

Grift R, Rijnsdorp AD, Barot S, Heino M, Dieckmann U (2003) Fisheries-induced trends in reaction norms for maturation in North Sea plaice. Mar Ecol Prog Ser 257:247-257

Guénette S, Lauck T, Clark C (1998) Marine reserves: from Beverton and Holt to the present. Rev Fish Biol Fish 8: 251-272

Gulland JA (1971) The fish resources of the ocean. Fishing News (Books), West Byfleet

Harrell FEJ (2001) Overview of maximum likelihood estimation. Springer Verlag, New York

Hauck M, Kroese M (2006) Fisheries compliance in South Africa: a decade of challenges and reform 1994-2004. Mar Pol 30(1):74-83

Hawkins JP, Roberts CM (2004) Effects of fishing on sex-changing Caribbean parrotfishes. Biol Conserv 115:213-226

Hilborn R, Ludwig D (1993) The limits of applied ecology. Ecol Appl 3:550-552

Hilborn R, Walters CJ (1992) Qualitative fisheries stock assessment: choice, dynamics and uncertainty. Chapman $\&$ Hall, New York

Hirshfield MF (1980) An experimental analysis of reproductive effort and cost in the Japanese medaka, Oryzias laticeps. Ecology 61:282-292

Hutchings JA (2005) Life history consequences of overexploitation to population recovery in Northwest Atlantic cod (Gadus morhua). Can J Fish Aquat Sci 62:824-832

Jennings S, Marshall SS, Polunin NVC (1996) Seychelle's marine protected areas: comparative structure and status of reef fish communities. Biol Cons 75:201-209

Jørgensen T (1990) Long-term changes in age at sexual maturity of North-East Arctic cod (Gadus morhua L.). J Cons Int Explor Mer 46:235-248

Kamler E (2005) Parent-egg-progeny relationships in teleost fishes: an energetic perspective. Rev Fish Biol Fish 15: 399-421

Kerwath SE, Götz A, Attwood CG, Sauer WHH (2007a) Area utilization and activity patterns of roman, Chrysoblephus laticeps (Sparidae), in a small marine protected area. Afr J Mar Sci 29:259-270

> Kerwath SE, Götz A, Attwood CG, Sauer WHH (2007b) Movement pattern and home range of roman Chrysoblephus laticeps. Afr J Mar Sci 29:93-103

Klima EF, Roberts TW, Jones AC (1986) Overview of the Tortugas sanctuary studies. N Am J Fish Manag 6:297-300

> Leaman BM (1991) Reproductive styles and life history variables relative to exploitation and management of Sebastes stocks. Environ Biol Fishes 30:253-271

Lechanteur YARG (2004) Spatial distribution, relative abundance and size distribution of suprabenthic linefish species present over subtidal reef along the Cape Peninsula National Park coastline. Center for Marine Studies, University of Cape Town

Lemm S, Altwood CG (2003) State of marine protected area management in South Africa. World Wildlife Fund, Stellenbosch

Lenfant P (2003) Demographic and genetic structures of white sea bream populations (Diplodus sargus, Linnaeus, 1758) inside and outside a Mediterranean marine reserve. C R Biol 326:751-760
Lenfant P, Planes S (2002) Temporal genetic changes between cohorts in a natural population of a marine fish, Diplodus sargus. Biol J Linn Soc 76:9-20

Lloret J, Planes S (2003) Condition, feeding and reproductive potential of white seabream Diplodus sargus as indicators of habitat quality and the effect of reserve protection in the northwestern Mediterranean. Mar Ecol Prog Ser 248:197-208

Magnan P, Proulx R, Plante M (2005) Integrating the effects of fish exploitation and interspecific competition into current life history theories: an example with lacustine brook trout (Salvelinus fontinalis) populations. Can J Fish Aquat Sci 62:747-757

Maliao RJ, Webb EL, Jensen KR (2004) A survey of stock of the donkey's ear abalone, Haliotis asinina L. in the Sagay Marine Reserve, Philippines: evaluating the effectiveness of marine protected area enforcement. Fish Res 66: 343-353

McCullagh P, Nelder JA (1995) Generalized linear models. Chapman and Hall, London

McGovern JC, Wyanski DM, Pashuk O, Manooch CS, Sedberry GR (1998) Changes in the sex ratio and size at maturity of gag Mycteroperca microlepis, from the Atlantic coast of the southeastern United States during 1976-1995. Fish Bull (Wash D C) 96:797-807

Muth KM, Wolfert DR (1986) Changes in growth and maturity of walleyes associated with stock rehabilitation in western Lake Erie, 1964-1983. N Am J Fish Manage 6:168-175

> Myers RA, Bowenand KG, Barrowman NJ (1999) Maximum reproductive rate of fish at low population sizes. Can J Fish Aquat Sci 56:2404-2419

> Olsen EM, Heino M, Lilly GR, Morgan MJ, Brattey J, Ernande B, Diekmann U (2004) Maturation trends indicative of rapid evolution preceded the collapse of northern cod. Nature 428:932-935

Olsen EM, Lilly GR, Heino M, Morgan MJ, Brattey J, Dieckmann U (2005) Assessing changes in age and size at maturation in collapsing populations of Atlantic cod (Gadus morhua). Can J Fish Aquat Sci 62:811-823

Pérez-Ruzafa Á, González-Wangüemert M, Lenfant P, Marcos C, García-Charton JA (2006) Effects of fishing protection on the genetic structure of fish populations. Biol Conserv 129:244-255

Peterman RM, Steer GJ, Bradford MJ (1985) Densitydependent catchability coefficients. Trans Am Fish Soc 114:438-440

Policansky D (1993) Fishing as a cause of evolution in fishes. In: Stokes TK, McGlade JM, Law R (eds) The exploitation of evolving resources. Springer Verlag, Berlin, p 2-18

Pritchard PC (1993) Undiscovered diamonds for the crown jewels. Oceanus 36:3-5

Ricker WE (1969) Effects of size-selective mortality and sampling bias on estimates of growth, mortality, production and yield. J Fish Res Board Can 26:479-541

Ricker WE (1981) Changes in the average size and average age of Pacific salmon. Can J Fish Aquat Sci 38:1636-1656

$>$ Rijnsdorp AD (1993) Fisheries as a large-scale experiment on life-history evolution: disentangling phenotypic and genetic effects in changes in maturation and reproduction of North Sea plaice, Pleuronectes platessa L. Oecologia 96: 391-401

Rijnsdorp AD, Grift RE, Kraak SBM (2005) Fisheries-induced adaptive change in reproductive investment in North Sea plaice (Pleuronectes platessa)? Can J Fish Aquat Sci 62: 833-843

Roberts CM, Hawkins JP (2000) Fully-protected marine reserves: a guide WWF Endangered Seas Campaign. Uni- 
versity of York

Robertson DR (1972) Social control of sex reversal in a coral reef fish. Science 177:1007-1009

Robertson DR, Choat JA, Posada JM, Ackerman JL (2005) Ocean surgeonfish Acanthurus bahianus. II. Fishing effects on longevity, size and abundance? Mar Ecol Prog Ser 295:245-256

Rose KA, Cowan JH, Winemiller KO, Myers JM, Hilborn R (2001) Compensatory density dependence in fish populations: importance, controversy, understanding and prognosis. Fish Fish 2:293-327

Sakai Y, Kohda M (1997) Harem structure of the protogynous angelfish, Centropyge ferrugatus (Pomacanthidae). Environ Biol Fishes 49:333-339

Sakai Y, Kohda M, Kuwamura T (2001) Effect of changing harem on timing of sex change in female cleaner fish Labroides dimidiatus. Anim Behav 62:251-257

Sánchez Lizaso JL, Goñi R, Reñones O, García-Charton JA and others (2000) Density dependence in marine protected populations: a review. Environ Conserv 27:144-158

Shapiro DY (1980) Serial female sex changes after simultaneous removal of males from social groups of a coral reef fish. Science 209:1136-1137

Sinclair AF, Swain DP, Hanson JM (2002) Disentangling the effects of size-selective mortality, density, and temperature on length-at-age. Can J Fish Aquat Sci 59:372-382

Smith MKS (2005) Towards a new approach for coastal governance with an assessment of the Plettenberg Bay linefisheries. MSc dissertation, Rhodes University, Grahamstown

Thresher RE, Gunn JS (1986) Comparative analysis of visual

Initial editorial responsibility: Howard Browman, Storebø, Norway; Final editorial responsibility: Matthias Seaman, Oldendorf/Luhe, Germany census techniques for highly mobile, reef associated piscivores (Carangidae). Environ Biol Fishes 17:93-116

Tilney RL, Nelson G, Radloff SE, Buxton CD (1996) Ichthyoplankton distribution and dispersal in the Tsitsikamma National Park marine reserve, South Africa. S Afr J Mar Sci $17: 1-14$

Toresen R (1986) Length and age at maturity of Norwegian spring spawning herring for the year classes 1959-1961 and 1973-1978. ICES CM 1986: H42

Trippel EA (1995) Age at maturity as a stress indicator in fisheries. Bioscience 45:759-771

Tyler AV, Dunn RS (1976) Ration, growth and measures of somatic and organ condition in relation to meal frequency in winter flounder, Pseudopleuronectes americanus, with hypotheses regarding population homeostasis. J Fish Res Board Can 33:63-75

Van Der Lingen CD, Fréon P, Fairweather TP, Van Der Westhuizen JJ (2006) Density-dependent changes in reproductive parameters and condition of southern Benguela sardine Sardinops sagax. Afr J Mar Sci 28:625-636

Ward RD, Woodwark M, Skibinsky DOF (1994) A comparison of genetic diversity levels in marine, freshwater, and anadromous fishes. J Fish Biol 44:213-232

Weatherley AH (1972) Growth processes in fish. In: Weatherley $\mathrm{AH}$ (ed) Growth and ecology of fish populations. Academic Press, London, p 73-128

> Wootton RJ (1977) Effect of food limitation during the breeding season on the size, body components and egg production of female sticklebacks (Gasterosteus aculeatus L.). J Anim Ecol 46:823-834

Submitted: April 13, 2007; Accepted: January 21, 2008 Proofs received from author(s): June 4, 2008 